\title{
Economic Load Dispatch by Hybrid Swarm Intelligence Based Gravitational Search Algorithm
}

\author{
Hari Mohan Dubey ${ }^{1}$, Manjaree Pandit ${ }^{2}$, B.K. Panigrahi ${ }^{3}$, Mugdha Udgir $^{4}$ \\ ${ }^{1,2,4}$ Department of Electrical Engineering, Madhav Institute of Technology \& science Gwalior, India \\ ${ }^{3}$ Department of Electrical Engineering, Indian Institute of Technology Delhi, India \\ E-mail: harimohandubey@rediffmail.com,manjaree_p@hotmail.com,bkpanigrahi@ee.iid.ac.in, \\ mughaudgir@gmail.com
}

\begin{abstract}
This paper presents a novel heuristic optimization method to solve complex economic load dispatch problem using a hybrid method based on particle swarm optimization (PSO) and gravitational search algorithm (GSA). This algorithm named as hybrid PSOGSA combines the social thinking feature in PSO with the local search capability of GSA. To analyze the performance of the PSOGSA algorithm it has been tested on four different standard test cases of different dimensions and complexity levels arising due to practical operating constraints. The obtained results are compared with recently reported methods. The comparison confirms the robustness and efficiency of the algorithm over other existing techniques.
\end{abstract}

Index Terms - PSOGSA, Economic Load Dispatch, Ramp Rate Limits, Prohibited Operating Zones (POZ)

\section{Introduction}

Economic Load Dispatch (ELD) Problem determines the schedule of generation which minimizes the total generation and operation cost while satisfying the load demand and operational constraints of all generating units. As this problem is having a both complex and nonlinear characteristic with heavy equality and inequality constraints [1].However modern generating units have higher order non-linearities and discontinuities in input-output characteristics due to valve point loading, ramp rate limits and prohibited operating zones[2]-[4], which makes the finding of optimal solution very hard.

Classical optimization methods such as lambda iteration, base point and gradient method [5]-[6] were employed to solve the ELD problem. Lambda iteration method is the most commonly used, but for the effectiveness of this method, the formulation needs to be continuous. Dynamic programming [7] has been used to solve ELD problem with valve point effect but it is time consuming, computationally extensive and unnecessarily increases the dimension of the problem.
Due to the inadequacy of these methods to stuck to the local solution instead of global ones, artificial intelligence techniques are used to solve ELD problem, these techniques include Genetic algorithm (GA) [8], Particle Swarm (PSO) [8], Evolutionary Programming (EP) [9], Differential Evolution (DE)[10], Hopfield neural network (HNN)[11]. Other techniques are New Particle Swarm with Local Random Search (NPSO_LRS)[12], Self-Organizing Hierarchical Particle Swarm Optimization (SOH_PSO)[13], Bacterial Foraging Optimization Nelder Mead Hybrid Algorithm (BFONM)[14], Biogeography based optimization (BBO) [15], continuous Quick Group Search Optimizer (QGSO) [16], Chemo tactic Differential Evolution Algorithm (BF_DE hybrid)[17], Hybrid swarm intelligence harmony search (HHS)[18], Firefly algorithm (FA)[19], Artificial bee colony optimization(ABC)[22].These optimization methodologies have been applied successfully to solve economic load dispatch problem.

Here, a new population based hybrid algorithm (PSOGSA) is implemented to solve economic dispatch problem. The PSOGSA algorithm incorporates some features of particle swarm optimization algorithm into gravitational search algorith $m$ i.e. exploitation ability of PSO with ability of exploration in GSA to unify their strength. The agents are initialized randomly and each agent in the search space is attracted towards the agent having a good solution. The agents near the optimal solution moves more slowly and assures the exploitation step of algorithm. Here gbest is used to exploit the global best. The position and velocity are updated until it reaches to the stopping criterion.

To validate the effectiveness of PSOGSA algorithm ELD problem with smooth and non-smooth cost function are considered in this paper. Non- smooth cost function includes generator capacity constraints, ramp rate limits, prohibited operating zones and losses whereas smooth cost function considers generator capacity constraints and power balance constraints with and without power loss.

The paper is organized as: sections 2 emphasize on 
the ELD problem with various practical constraints, section 3 gives a brief description about the PSOGSA algorithm. Section 4 presents the implementation of PSOGSA for ELD problem. In section 5 simulation results for our test cases are compared with the other recently reported methods. Finally the conclusion is drawn in section 6 .

\section{Problem Formulation}

The aim of economic load dispatch problem is to minimize the overall cost of production of power generation while satisfying power balance, generator constraints with ramp rate limits and prohibited operating zones. The objective function is usually stated as quadratic function. Mathematically the problem is formulated as:

$$
\min f=\sum_{i=1}^{N_{G}} F_{i}\left(P_{i}\right)
$$

where

$$
F_{i}\left(P_{i}\right)=a_{i} P_{i}^{2}+b_{i} P_{i}+c_{i}
$$

Where $F_{i}$ is the total generating cost of $i^{\text {th }}$ generating unit and $a_{i}, b_{i}$ and $c_{i}$ are the coefficients of $i^{\text {th }}$ generator. $P_{i}$ is the real power output (MW) of $i^{\text {th }}$ generator corresponding to time $t, \mathrm{~N}_{\mathrm{G}}$ is the total number of generating units. The ELD problem discussed is subjected to the following constraints:

\subsection{Power Balance Constraints:}

$$
\sum_{i=1}^{N_{G}} P_{i}=P_{D}+P_{L}
$$

Where $P_{D}$ is total load demand and $P_{L}$ is the total transmission loss. $\mathrm{P}_{\mathrm{L}}$ is calculated using $\mathrm{B}$ - coefficients, given by-

$$
P_{L}=\sum_{i=1}^{N_{G}} \sum_{j=1}^{N_{G}} P_{i} B_{i j} P_{j}
$$

\subsection{Generator Constraints:}

The power output of each unit is restricted by its upper $\mathrm{P}^{\max }$ and lower $\mathrm{P}^{\min }$ limits of real power generation and is given by-

$$
P_{i}^{\min } \leq P_{i} \leq P_{i}^{\max }
$$

\subsection{Ramp rate limits:}

When the ramp rate limits are considered, the generator operation constraints (5) are modified as follows:

$$
\begin{aligned}
& \max \left(P_{i}^{\min }, U R_{i}-P_{i}\right) \leq \\
& \quad P_{i} \leq \min \left(P_{i}^{\max }, P_{i}^{0}-D R_{i}\right)
\end{aligned}
$$

Where $P_{i}$ is the current output power of $i^{\text {th }}$ unit and $\mathrm{P}_{\mathrm{i}}{ }^{\mathrm{o}}$ is the power generation of $\mathrm{i}^{\mathrm{t}}$ unit at previous hour and $\mathrm{UR}_{\mathrm{i}}$ and $\mathrm{DR}_{\mathrm{i}}$ are the up and down ramp rate limits respectively.

\subsection{Prohibited Operating Zone:}

A unit with prohibited operating zone has discontinuous cost characteristics. So the unit operation is avoided in prohibited zones. The concept of prohibited operating zone considers the following constraints:

$$
\left.\begin{array}{l}
P_{i}^{\min } \leq P_{i} \leq P_{i, 1}^{L}\left(i=1,2, \ldots, N_{G}\right) \\
P_{i, j-1}^{U} \leq P_{i} \leq P_{i, j}^{L}\left(j=2,3, \ldots, N_{Z i}\right)\left(i=1,2, \ldots, N_{G}\right) \\
P_{i, N_{Z i}}^{U} \leq P_{i} \leq P_{i}^{\max }\left(i=1,2, \ldots, N_{G}\right)
\end{array}\right\}
$$

Where $\mathrm{P}_{\mathrm{i}} \mathrm{U}_{\mathrm{j}-1}$ and $\mathrm{P}_{\mathrm{i}}^{\mathrm{L}}{ }_{\mathrm{j}}$ are the upper and lower boundaries of $j^{\text {th }}$ prohibited zone of $i^{\text {th }}$ generator and $\mathrm{N}_{\mathrm{Zi}}$ is the number of prohibited zones of $\mathrm{i}^{\text {th }}$ generator.

\section{Hybrid Algorithm (PSOGSA)}

PSOGSA is formulated by S. Mirjalili et al. in 2010[20]. The basic concept behind the hybridization is to combine the ability of social thinking (gbest) in PSO using the local search capability of GSA.

The proposed algorithm considers the agents as objects and the position of $\mathrm{i}^{\text {th }}$ agent is given by-

$$
X_{i}=\left(x_{i}^{1}, \ldots, x_{i}^{d}, \ldots, x_{i}^{n}\right) i=1,2, \ldots, N
$$

Where $x_{i}{ }^{d}$ is the position in the $d^{\text {th }}$ dimension of the $i^{\text {th }}$ agent (mass).

The masses are described randomly and the force acting on mass $i$ from mass $j$ is given as -

$$
F_{i j}^{d}(t)=G(t) \frac{M_{i}(t) \times M_{j}(t)}{R_{i j}(t)+\varepsilon}\left(x_{j}^{d}(t)-x_{i}^{d}(t)\right)
$$

Where $\mathrm{Mi}(\mathrm{t})$ and $\mathrm{Mj}(\mathrm{t})$ are masses of objects $\mathrm{I}$ and $\mathrm{j}$, $\mathrm{G}(\mathrm{t})$ is the gravitational constant at time $\mathrm{t}, \varepsilon$ is a small constant, Rij(t) is the Euclidean distance between I and $j$ objects.

$$
R_{i j}(t)=\left\|X_{i}(t), X_{j}(t)\right\|_{2}
$$


Gravitational constant $\mathrm{G}(\mathrm{t})$ is in itialized randomly in the beginning and is reduced with time to control the search accuracy.

$$
G(t)=G_{0} e^{\alpha \frac{t}{T}}
$$

It means $G$ is the function of time $t$ and in itial value G0, where $G_{0}$ is the initial value of gravitational constant, $\alpha$ is the user specified constant and $\mathrm{T}$ is the maximum number of iterations and $\mathrm{t}$ is the current iteration.

Let the total force acting on agent $\mathrm{i}$ in the dimension $\mathrm{d}$ is described as-

$$
F_{i}^{d}(t)=\sum_{j=1, j \neq 1}^{N} \operatorname{rand}_{i} F_{i j}^{d}(t)
$$

Where, $\operatorname{rand}_{j}$ is a random number between the interval $[0,1]$.

The acceleration of $i^{\text {th }}$ agent at iteration $t$ having $d$ dimension is given by the law of motion-

$$
\alpha c_{i}^{d}(t)=\frac{F_{i}^{d}(t)}{M_{i}(t)}
$$

The velocity of an agent is calculated as -

$$
\begin{aligned}
& v_{i}^{d}(t+1)=w \cdot v_{i}^{d}(t) c_{1}^{\prime} \times \operatorname{rand} \times \alpha c_{i}^{d}(t) \\
& +c_{2}^{\prime} \times \operatorname{rand} \times\left(\text { gbest }-x_{i}^{d}(t)\right)
\end{aligned}
$$

Where $v_{i}{ }^{d}(t)$ is the velocity of agent $i$ at iteration $t$ in dimension $\mathrm{d}, \mathrm{c}_{\mathrm{j}}{ }^{\prime}$ is a weighting factor, $\mathrm{w}$ is a weighting function, rand is a random number between 0 and 1 , $\alpha c_{i}^{d}(t)$ is the acceleration of $i^{\text {th }}$ agent at iteration $t$ in dimension $\mathrm{d}$ and gbest is the best solution found so far.

At each, iteration the position of an agent is calculated as-

$$
x_{i}^{d}(t+1)=x_{i}^{d}(t)+v_{i}^{d}(t+1)
$$

Where $v_{i}^{d}(t+1)$ is the velocity of next agent and $x_{i}{ }^{d}$ is the position of $i^{\text {th }}$ agent in $\mathrm{d}^{\text {th }}$ dimension at iteration $\mathrm{t}$.

The value of masses of agents are calculated by comparis on of fitness-

$$
\begin{aligned}
m_{i}(t)= & \\
& \frac{\text { currentfitness }_{i}(t)-0.99 * \operatorname{worst}(t)}{\operatorname{best}(t)-\operatorname{worst}(t)} \\
& i=1,2, \ldots, n
\end{aligned}
$$

$$
M_{i}(t)=\frac{m_{i}(t) * 5}{\sum_{j=1}^{n} m_{j}(t)}
$$

Where current-fitness $s_{i}(t)$ is the fitness value of the agent $\mathrm{i}$ at any time $\mathrm{t}$, and best $(\mathrm{t})$ and worst $(\mathrm{t})$ are the minimum and maximu $\mathrm{m}$ fitness value of all agents.

The agents exploring in the search space are attracted towards other agents by means of gravity force and causes a movement to the agents having heavier mass. The heavier mass represents a good solution. Here gbest help them in finding the optima around a good solution. The optimal solution is found by using the exploitation ability of PSO. Global search and local search balance is accomplished by adjusting the values $\mathrm{C} 1$ and $\mathrm{C} 2$.

IV. Implementation of PSOGSA Algorithm for Economic Load Dispatch

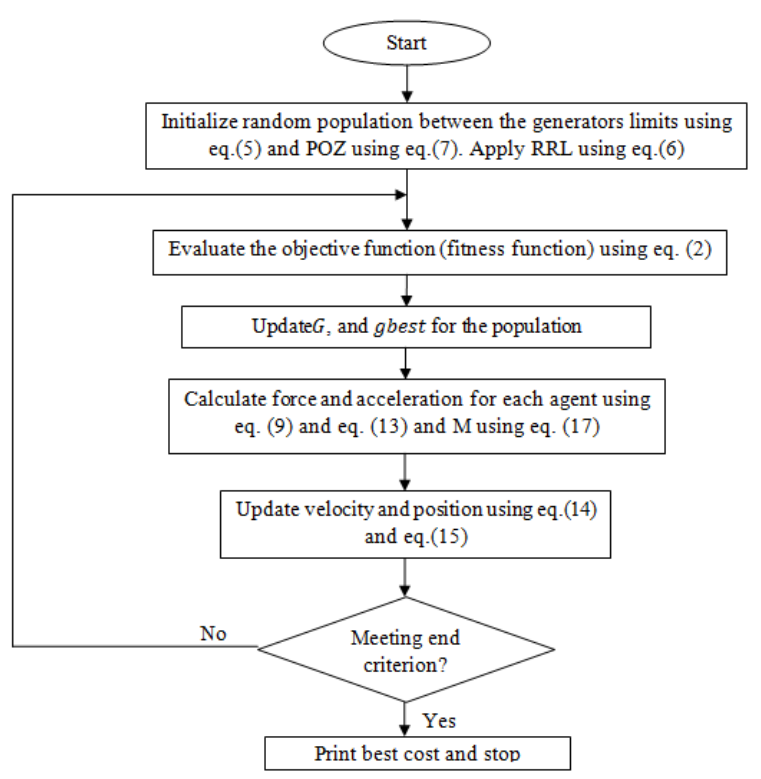

Fig. 1: Flow chart of PSOGSA approach for ELD

\section{Step1: Search space identification}

In this agents are randomly initialized and located between the minimu $\mathrm{m}$ and maximu m operating limits of generators. Each agent should satisfy the constraints given by "(3)" and "(5)".

\section{Step 2: Fitness evaluation}

This evaluates fitness for each agent using "(2)" while constraints are satisfied. Update $\mathrm{G}$ and gbest for the population.

\section{Step 3: Agent force calculation}

In this total force acting on agent $\mathrm{i}$ in different dimensions is calculated using "(9)". 


\section{Step 4: Evaluation of mass and acceleration of an agent}

The acceleration of $i^{\text {th }}$ agent in $\mathrm{d}$ dimension is calculated using "(13)" and mass is calculated using “(17)".

\section{Step 5: Update velocity and position of agents}

The next velocity of agent is calculated using "(14)" and position is updated using "(15)".

\section{Step 6: Stopping criteria}

Repeat process 2 to 5 until stopping criteria is met.

In this paper maximum number of iterations is the stopping criteria. The step by step process involved to solve ELD problem using PSOGSA approach is shown with the help of flow chart in figure 1.

\section{Case Studies and Numerical Results}

To validate the effectiveness of hybrid PSOGSA approach, four standard test cases having different properties were considered. These are a 6 unit system with POZ and ramp rate limits, an 18 unit system with varying percentage of maximum demand, a 20 unit system with losses and a large scale 54 unit system. The algorith $m$ is implemented in MATLAB 7.8 and the system configuration is Intel core i3 processor with $2.3 \mathrm{GHz}$ speed and 2GB RAM.

\subsection{Test case I: Six unit system}

The system contains six generating units. The input data for this system is taken from [8]. The load demand is set as $1263 \mathrm{MW}$. In this system transmission loss, POZ and ramp rate limits are also considered. The experimental result obtained from PSOGSA approach, Hybrid SI based Harmony Search (HHS) [18], and Biogeography Based Optimization (BBO) [15] and Self-Organizing Hierarchical Particle Swarm
Optimization (SOH_PSO) [13] are shown in Table 1. (2) shows the convergence characteristic of the six unit systemwith ramp rate limits, POZ and losses.

\subsection{Test case II: Eighteen unit system}

This test case contains Crete Island system of 18 generating units. The input data for this test case is taken from [21], and the maximu mower output for the system is $433.22 \mathrm{MW}$. The simulations were carried out with varying percentage of maximum power demand. Their best solutions using PSOGSA are shown in Table 2. The result obtained from PSOGSA approach, simulated annealing (SA) [23], artificial bee colony (ABC) [22] and other techniques is listed in Table 3. The convergence characteristics for eighteen unit systemobtained by PSOGSA approach is shown in (3).

\subsection{Test case III: Twenty unit system}

The system contains twenty generating units with loss coefficients. The input data for this test system is taken from [11].The system load demand is $2500 \mathrm{MW}$. The obtained results in terms of optimum power output and power loss using PSOGSA approach has been compared with General Algebraic Modeling System (GAMS) [24], Biogeography Based Optimization (BBO) [15] and other methods are shown in Table 4. Convergence characteristic of the 20 unit system with loss is shown in (4).

\subsection{Test case IV: Fifty four unit system}

A large scale IEEE 114 bus system consisting of 54 generating units is considered here. The load demand is set to $4242 \mathrm{MW}$. The input data for this system is taken from Dieu et al. 2012 [25]. The optimu m power output achieved by PSOGSA is presented in Table 5. The minimum cost obtained is compared with Augmented Lagrange Hopfield Network (HN) [25], Differential evolution (DE) [25], partic le swarm optimization (PSO) [25]. A convergence characteristic of 54 unit system is shown in (5).

Table 1: Result of Six Unit systems with RRL, POZ \& Loss

\begin{tabular}{|c|c|c|c|c|}
\hline Unit & SOH-PSO & BBO & HHS & PSOGSA \\
\hline $\mathrm{Pg} 1$ & 438.21 & 447.3997 & 449.9094 & 447.5144 \\
\hline $\mathrm{Pg} 2$ & 172.58 & 173.2392 & 172.7347 & 173.1461 \\
\hline $\mathrm{Pg} 3$ & 257.42 & 263.3163 & 262.9643 & 263.3337 \\
\hline $\mathrm{Pg} 4$ & 141.09 & 138.0006 & 136.03 & 138.9189 \\
\hline $\mathrm{Pg} 5$ & 179.37 & 165.4104 & 166.967 & 165.3541 \\
\hline $\mathrm{Pg} 6$ & 86.88 & 87.07979 & 86.8778 & 87.1269 \\
\hline $\mathrm{O} / \mathrm{P}(\mathrm{MW})$ & 1275.55 & 1275.446 & 1275.4832 & 1275.3941 \\
\hline $\mathrm{P}$ loss & 12.55 & 12.446 & 12.4834 & 12.39404 \\
\hline Cost $(\$ / \mathrm{hr})$ & 15446.02 & 15443.0963 & 15442.8313 & 15442.3931 \\
\hline
\end{tabular}




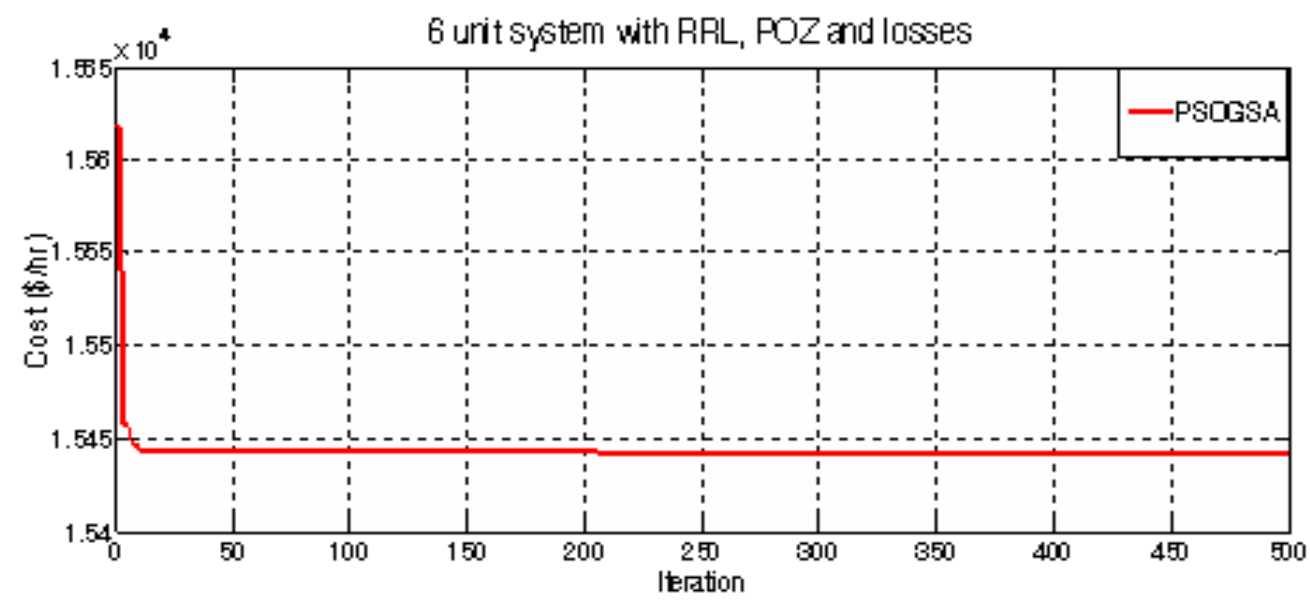

Fig. 2: Convergence characteristics of 6 unit system

Table 2: Results for eighteen unit system using PSOGSA

\begin{tabular}{|c|c|c|c|c|}
\hline Unit & $0.70 * \mathrm{MD}$ & $0.80 * \mathrm{MD}$ & $0.90 * \mathrm{MD}$ & $0.95 * \mathrm{MD}$ \\
\hline $\mathrm{Pg} 1$ & 15.0000 & 15.0000 & 15.0000 & 15.0000 \\
\hline $\mathrm{Pg} 2$ & 44.6316 & 45.0000 & 45.0000 & 45.0000 \\
\hline $\mathrm{Pg} 3$ & 25.0000 & 25.0000 & 25.0000 & 25.0000 \\
\hline $\mathrm{Pg} 4$ & 25.0000 & 25.0000 & 25.0000 & 25.0000 \\
\hline Pg5 & 25.0000 & 25.0000 & 25.0000 & 25.0000 \\
\hline Pg6 & 3.0000 & 3.0000 & 8.2149 & 13.7055 \\
\hline $\mathrm{Pg} 7$ & 3.0000 & 3.0000 & 8.2195 & 13.7069 \\
\hline Pg8 & 12.2800 & 12.2800 & 12.2800 & 12.2800 \\
\hline $\mathrm{Pg} 9$ & 12.2800 & 12.2800 & 12.2800 & 12.2800 \\
\hline Pg10 & 12.2800 & 12.2800 & 12.2800 & 12.2800 \\
\hline Pg11 & 12.2800 & 12.2800 & 12.2800 & 12.2800 \\
\hline Pg12 & 14.8842 & 20.7256 & 24.0000 & 24.0000 \\
\hline Pg13 & 3.0000 & 3.0000 & 3.1481 & 6.4138 \\
\hline Pg14 & 21.1318 & 30.8653 & 36.2000 & 36.2000 \\
\hline Pg15 & 23.2361 & 32.3543 & 42.4920 & 45.0000 \\
\hline Pg16 & 24.1260 & 33.2650 & 37.0000 & 37.0000 \\
\hline Pg17 & 24.1243 & 33.2458 & 43.3525 & 45.0000 \\
\hline Pg18 & 3.0000 & 3.0000 & 3.1510 & 6.4127 \\
\hline $\mathbf{O} / \mathbf{P}(\mathbf{M W})$ & 303.254 & 346.576 & 389.898 & 411.5589 \\
\hline Min $\operatorname{cost}(\$ / h r)$ & 20386.2157 & 23855.2865 & 27653.7507 & 29731.0666 \\
\hline Avg. $\operatorname{cost}(\$ / h r)$ & 20386.2360 & 23855.28655 & 27653.7893 & 29731.0666 \\
\hline SD & 0.0372 & 0.0001 & 0.0253 & 0.0000 \\
\hline Time/Iter (sec) & 0.0280 & 0.0215 & 0.0187 & 0.0158 \\
\hline
\end{tabular}

Table 3: Comparison of results ( 18 unit system $M D=433.22 \mathrm{MW}$ )

\begin{tabular}{|c|c|c|c|c|}
\hline Method & $\mathbf{0 . 7 0} * \mathbf{M D}$ & $\mathbf{0 . 8 0} * \mathbf{M D}$ & $\mathbf{0 . 9 0} * \mathbf{M D}$ & $\mathbf{0 . 9 5} * \mathbf{M D}$ \\
\hline$\lambda$ _ Iteration & 20393.48 & 23861.58 & 27652.47 & 29731.05 \\
\hline Binary GA & 20444.68 & 23980.24 & 27681.05 & 29733.42 \\
\hline RGA & 20396.39 & 23861.58 & 27655.53 & 29731.05 \\
\hline ABC & 20391.60 & 23589.40 & 27653.60 & 29730.80 \\
\hline SA & 20386.309 & 23855.855 & 27653.78 & 29731.066 \\
\hline PSOGSA & 20386.2157 & 23855.2865 & 27653.75 & 29731.066 \\
\hline
\end{tabular}




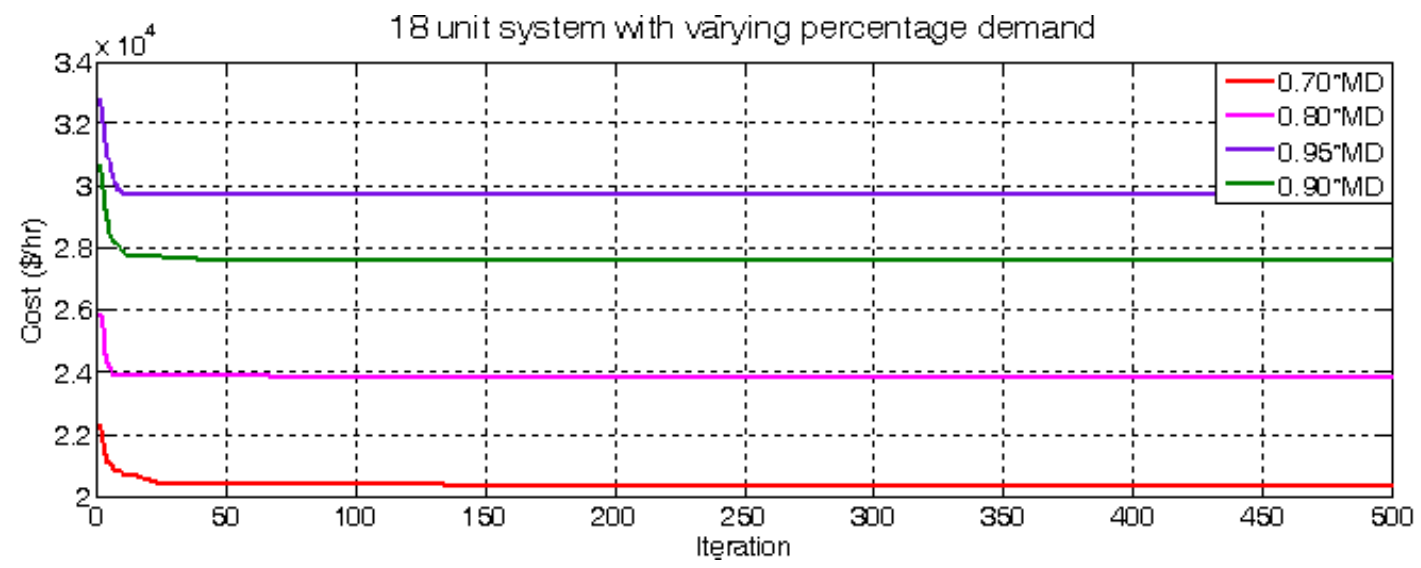

Fig. 3: Convergence characteristics of 18 unit system

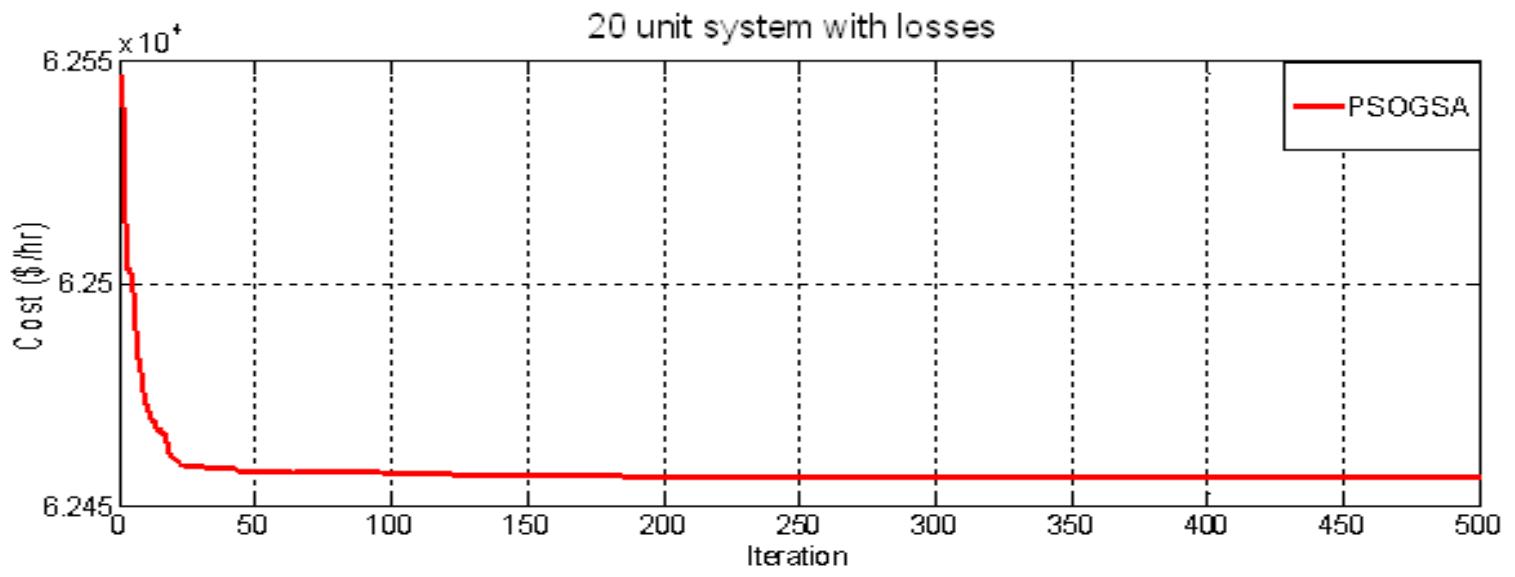

Fig. 4: Convergence characteristic of 20 unit system

Table 4: Result of 20 unit systems with losses

\begin{tabular}{|c|c|c|c|c|}
\hline Unit & BBO & GAMS & Q GSO & PSOGSA \\
\hline Pg1 & 513.0892 & 512.782 & 512.7303 & 512.7788 \\
\hline Pg2 & 173.3533 & 169.102 & 169.0263 & 169.0469 \\
\hline Pg3 & 126.9231 & 126.891 & 126.8806 & 126.8915 \\
\hline Pg4 & 103.3292 & 102.867 & 102.8723 & 102.8666 \\
\hline Pg5 & 113.7741 & 113.683 & 113.6836 & 113.6839 \\
\hline Pg6 & 73.06694 & 73.572 & 73.5741 & 73.5798 \\
\hline Pg7 & 114.9843 & 115.290 & 115.3037 & 115.2981 \\
\hline Pg8 & 116.4238 & 116.400 & 116.4090 & 116.4039 \\
\hline Pg9 & 100.6948 & 100.405 & 100.4303 & 100.4041 \\
\hline Pg10 & 99.99979 & 106.027 & 106.0581 & 106.0575 \\
\hline Pg11 & 148.977 & 150.239 & 150.2337 & 150.2512 \\
\hline Pg12 & 294.0207 & 292.766 & 292.7813 & 292.7548 \\
\hline Pg13 & 119.5754 & 119.114 & 119.1165 & 119.1124 \\
\hline Pg14 & 30.54786 & 30.832 & 30.8179 & 30.8350 \\
\hline Pg15 & 116.4546 & 115.805 & 115.8179 & 115.8097 \\
\hline Pg16 & 36.22787 & 36.254 & 36.2542 & 36.2548 \\
\hline Pg17 & 66.85943 & 66.859 & 66.8611 & 66.8649 \\
\hline Pg18 & 88.54701 & 87.971 & 87.9696 & 87.9650 \\
\hline Pg19 & 100.9802 & 100.803 & 100.8088 & 100.7982 \\
\hline Pg20 & 54.2725 & 54.305 & 54.3106 & 54.3083 \\
\hline P Loss & 92.1011 & 91.967 & $\mathbf{9 1 . 9 6 5}$ & $\mathbf{9 1 . 9 6 5 4}$ \\
\hline O/P(MW) & 2592.1011 & 2591.967 & $\mathbf{2 5 9 1 . 9 6 5}$ & $\mathbf{2 5 9 1 . 9 6 5 4}$ \\
\hline Min Cost (\$/hr) & 62456.7926 & 62456.633 & $\mathbf{6 2 4 5 6 . 6 3 3 0}$ & $\mathbf{6 2 4 5 6 . 6 3 3 0 9}$ \\
\hline
\end{tabular}


Table 5: Result of 54 units System

\begin{tabular}{|c|c|c|c|}
\hline Unit & PSOGSA & Unit & PSOGSA \\
\hline Pg1 & 30.0000 & Pg30 & 80.0000 \\
\hline $\mathrm{Pg} 2$ & 30.0000 & $\mathrm{Pg} 31$ & 46.4558 \\
\hline Pg3 & 30.0000 & Pg32 & 30.0000 \\
\hline $\mathrm{Pg} 4$ & 30.0000 & Pg33 & 20.0000 \\
\hline Pg5 & 150.0000 & $\mathrm{Pg} 34$ & 20.0000 \\
\hline Pg6 & 156.0356 & Pg35 & 100.0000 \\
\hline $\mathrm{Pg} 7$ & 30.0000 & Pg36 & 88.2642 \\
\hline Pg8 & 100.0000 & Pg37 & 150.0000 \\
\hline $\mathrm{Pg} 9$ & 30.0000 & Pg38 & 30.0000 \\
\hline Pg11 & 30.0000 & Pg39 & 234.5160 \\
\hline Pg12 & 100.0000 & $\mathrm{Pg} 40$ & 212.3911 \\
\hline Pg13 & 124.5674 & $\mathrm{Pg} 41$ & 20.0000 \\
\hline Pg14 & 30.0000 & $\operatorname{Pg} 42$ & 50.0000 \\
\hline Pg15 & 30.0000 & $\mathrm{Pg} 43$ & 100.0000 \\
\hline Pg16 & 69.8064 & $\mathrm{Pg} 44$ & 196.1548 \\
\hline Pg17 & 30.0000 & $\mathrm{Pg} 45$ & 100.0000 \\
\hline Pg18 & 86.6968 & $\mathrm{Pg} 46$ & 20.0000 \\
\hline Pg19 & 30.0000 & Pg47 & 58.1562 \\
\hline Pg20 & 30.0000 & $\operatorname{Pg} 48$ & 86.0867 \\
\hline $\mathrm{Pg} 21$ & 92.5384 & $\mathrm{Pg} 49$ & 20.0000 \\
\hline Pg22 & 108.1637 & $\operatorname{Pg} 50$ & 50.0000 \\
\hline Pg23 & 100.0000 & $\operatorname{Pg} 51$ & 100.0000 \\
\hline Pg24 & 100.0000 & Pg52 & 100.0000 \\
\hline $\mathrm{Pg} 25$ & 132.5493 & Pg53 & 100.0000 \\
\hline Pg26 & 77.0648 & $\operatorname{Pg} 54$ & 50.0000 \\
\hline Pg27 & 100.0000 & \multirow{3}{*}{$\begin{array}{c}\text { Min Cost } \\
(\$ / \mathbf{h r} \mathbf{)} \\
\text { Time/Iter } \\
(\mathrm{sec})\end{array}$} & \multirow{3}{*}{$\begin{array}{c}\mathbf{2 2 4 3 2 . 2 5 1 0} \\
0.0416\end{array}$} \\
\hline Pg28 & 100.0000 & & \\
\hline Pg29 & 156.8691 & & \\
\hline
\end{tabular}

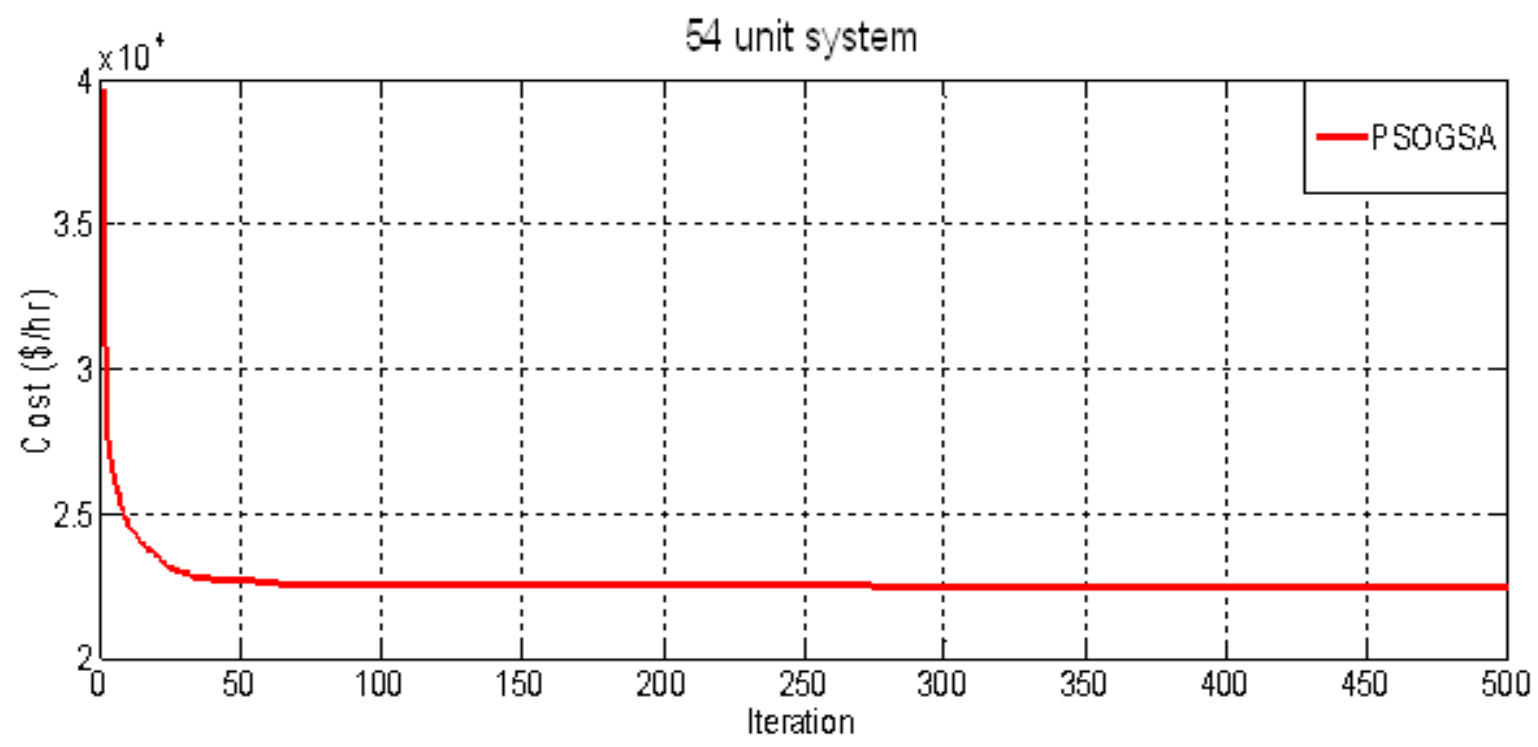

Fig. 5: Convergence characteristic of 54 unit system 


\section{Parameter Selection}

There are four important parameters in the hybrid PSOGSA algorithm: Gravitational constant $\left(\mathrm{G}_{0}\right)$, acceleration coefficient $(\alpha)$, weighting factor $(\mathrm{C} 1, \mathrm{C} 2)$ and population size (n). These parameters are selected in such a way that a s mooth convergence behavior is ensured. To obtain the optimal values of these parameters a detailed study was carried out by varying these parameters. For each combination 20 trials have been made with maximum number of iterations set to 500 per trial. Performance of PSOGSA is analyzed for a large scale 54 generating unit ELD problem.

Table 6: Effect of weighing factor $\mathrm{C} 1$ and $\mathrm{C} 2$ on Case 4 (20 trials)

\begin{tabular}{|c|c|c|c|c|c|c|}
\hline Case & C1 & $\mathrm{C2}$ & $\operatorname{Min} \operatorname{cost}(\$ / \mathrm{hr})$ & $\operatorname{Avg} \operatorname{cost}(\$ / h r)$ & Max cost $(\$ / h r)$ & SD \\
\hline 1. & \multirow{3}{*}{1.0} & 1.5 & 22432.3168 & 22432.5327 & 22432.4247 & 0.1079 \\
\hline 2. & & 2.0 & 22432.3443 & 22436.2074 & 22434.2758 & 1.9315 \\
\hline 3. & & 2.5 & 22432.2529 & 22452.2598 & 22442.2563 & 10.003 \\
\hline 4. & \multirow{3}{*}{1.5} & 1.5 & 22432.6282 & 22436.4184 & 22434.5233 & 1.8950 \\
\hline 5. & & 2.0 & 22432.2665 & 22432.3059 & 22432.2862 & 0.0196 \\
\hline 6. & & 2.5 & 22449.3487 & 22458.2204 & 22453.7845 & 4.4358 \\
\hline 7. & \multirow{3}{*}{2.0} & 1.5 & 22432.2510 & 22432.3347 & 22432.2928 & 0.0418 \\
\hline 8. & & 2.0 & 22432.2674 & 22432.3018 & 22432.2846 & 0.0172 \\
\hline 9. & & 2.5 & 22432.2529 & 22432.2561 & 22432.2545 & 0.0016 \\
\hline 10. & \multirow{3}{*}{2.5} & 1.5 & 22432.2709 & 22432.3706 & 22432.3207 & 0.0498 \\
\hline 11. & & 2.0 & 22432.2671 & 22432.2817 & 22432.2744 & 0.0073 \\
\hline 12. & & 2.5 & 22432.2641 & 22436.2362 & 22434.2501 & 1.9860 \\
\hline
\end{tabular}

The optimum parameters are selected as follows: population size $(n=10)$, gravitational constant $\left(\mathrm{G}_{0}\right)=1$ and acceleration coefficient $(\alpha)=10$ are initially considered. To analyze optimum value of weighting factor $\mathrm{c} 1$ and $\mathrm{c} 2$; the values of $\mathrm{C} 1$ varied between 1.0 and 2.5 with a step increase of 0.5 and $\mathrm{C} 2$ is varied from 1.5 to 2.5 with a step increase of 0.5 . The results of variation in $\mathrm{C} 1$ and $\mathrm{C} 2$ for obtaining minimum, maximu $m$ and average costs and the standard deviation for 20 trials are shown in Table 6. Best results were obtained when $\mathrm{C} 1=2.0$ and $\mathrm{C} 2=1.5$.

Table 7 lists the effect of acceleration coefficient $\alpha$ on the performance of the algorithm. Too large $\alpha$ is not capable in searching the minimum for the problem in addition to this it reduces the computational speed of the algorithm and increases standard deviation. For repeated 20 trial $\alpha=10$ resulted in achieving optimal solution.

Table 7: Effect of $\alpha$ on 54 unit System (case 4, 20 trials)

\begin{tabular}{|c|c|c|c|c|c|}
\hline Sr.No & $\boldsymbol{\alpha}$ & Min cost $\mathbf{( \$ \mathbf { h r } )}$ & Max cost $\mathbf{( \$ / h r )}$ & Avg cost $\mathbf{( \$ \mathbf { h r } )}$ & SD \\
\hline 1. & $\mathbf{1 0}$ & $\mathbf{2 2 4 3 2 . 2 5 1 0}$ & $\mathbf{2 2 4 3 2 . 3 3 4 7}$ & $\mathbf{2 2 4 3 2 . 2 9 2 8}$ & $\mathbf{0 . 0 4 1 8}$ \\
\hline 2. & 100 & 22455.3955 & 22550.7479 & 22503.0717 & 47.6761 \\
\hline 3. & 1000 & 23717.9908 & 23890.5514 & 23804.2711 & 86.2809 \\
\hline
\end{tabular}

Table 8: Effect of population size on 54 unit system (case 4, 20 trials)

\begin{tabular}{|c|c|c|c|c|c|}
\hline Sr.No & $\mathbf{n}$ & Min cost $\mathbf{( \$ \mathbf { h r } )}$ & Max cost $\mathbf{( \$ / h r )}$ & Avg cost $\mathbf{( \$ / h r )}$ & SD \\
\hline 1. & 50 & 22432.3948 & 22432.4233 & 22432.4085 & 0.0142 \\
\hline 2. & 100 & 22432.2510 & 22432.3347 & 22432.2928 & 0.0418 \\
\hline 3. & 150 & 22432.4186 & 22432.4223 & 22432.4204 & 0.0018 \\
\hline 4. & 200 & 22432.3456 & 22432.7407 & 22432.5431 & 0.1975 \\
\hline
\end{tabular}

Table 8 depicts the performance of PSOGSA algorithm for different population sizes. Test was carried out for repeated 20 trials with population size 50 , $100,150,200$.The study shows that too large population size makes the algorithm slow whereas with small population size average cost and standard deviation increases. Based on the simulation result it is concluded that $\mathrm{n}=100$ gives minimum generation cost. 
Table 9: Effect of G0 on 54 units System (case 4, 20 trials)

\begin{tabular}{|c|c|c|c|c|c|}
\hline Sr.No & $\mathbf{G}_{\mathbf{0}}$ & Min cost $\mathbf{( \$ / \mathbf { h r } )}$ & Max cost $\mathbf{( \$ / h r )}$ & Avg cost $\mathbf{( \$ / h r )}$ & SD \\
\hline 1. & 1 & 22432.2510 & 22432.3347 & 22432.2928 & 0.0418 \\
\hline 2. & 50 & 22432.5305 & 22432.5980 & 22432.5642 & 0.0337 \\
\hline 3. & 100 & 22432.4986 & 22432.8893 & 22432.6939 & 0.1953 \\
\hline 4. & 150 & 22432.8355 & 22433.0643 & 22432.9499 & 0.1143 \\
\hline 5. & 200 & 22432.7453 & 22433.2283 & 22432.9868 & 0.2414 \\
\hline
\end{tabular}

Table 9 shows the effect of $\mathrm{G}_{0}$ on the performance of hybrid PSOGSA algorithm. $\mathrm{G}_{0}$ was varied from 1 to 200 with a step increase of $50 . \mathrm{G}_{0}=1$ gives minimum generation cost. Increase in $\mathrm{G}_{0}$ beyond this value does not produce any significant improvement rather it increases standard deviation.

After a numerous careful experimentation the following values of PSOGSA parameters for all cases have been used.

$\mathrm{n}=100, \alpha=10, \mathrm{G}_{0}=1, \mathrm{C} 1=2.0, \mathrm{C} 2=1.5$.

\section{Comparative Study}

\section{A) Solution Quality}

As seen in the Table 1, 4 and 5 the minimum cost achieved by PSOGSA approach is $15442.3930 \$ / \mathrm{hr}$, $62456.63309 \$ / \mathrm{hr}, 22432.2510 \$ / \mathrm{hr}$ for test case I, III and IV. The minimum cost obtained for the test case II is listed in Table 2, 3 and the results are very close to the recent reported techniques. Over 20 repeated trials PSOGSA approach produce small standard deviation of evaluation values in all the test cases. Table 9, 11 and 12 shows that then average cost obtained by PSOGSA approach for the test case I, III and IV is less than the reported average cost of other methods. It is observed that PSOGSA provides better results as compared to other existing techniques.

Table 10: Comparison of convergence results for 6 unit System

\begin{tabular}{|c|c|c|c|c|}
\hline \multirow{2}{*}{ Method } & \multicolumn{3}{|c|}{ Generation Cost $\mathbf{( \$ / h r )}$} & \multirow{2}{*}{ S.D } \\
\cline { 2 - 4 } & Max & Min & Avg. & 0.0002 \\
\hline PSO & 15492 & 15450 & 15454 & 0.0570 \\
\hline GA & 15542 & 15459 & 15469 & NA \\
\hline NPSO-LRS & NA & 15450 & 15450.5 & 2.58223 \\
\hline ABF-NM & NA & 15443.8164 & 15446.95383 & NA \\
\hline DE & NA & 15449.766 & 15449.777 & NA \\
\hline SOH-PSO & 15609.64 & 15446.02 & 15497.35 & 0.0420 \\
\hline HHS & 15453 & 15449 & 15450 & NA \\
\hline BBO & 15443.096 & 15443.096 & 15443.096 & 1.8275 \\
\hline Hybrid SI-based HS & NA & 15442.8423 & 15446.7142 & $\mathbf{0 . 0 0 0 7}$ \\
\hline PSOGSA & $\mathbf{1 5 4 4 2 . 3 9 6 2}$ & $\mathbf{1 5 4 4 2 . 3 9 3 0}$ & $\mathbf{1 5 4 4 2 . 3 9 4 2 3}$ & \\
\hline
\end{tabular}

Table 11: Comparison of convergence result for 20 unit system

\begin{tabular}{|c|c|c|c|}
\hline \multirow{2}{*}{ Method } & \multicolumn{3}{|c|}{ Generation Cost(\$/hr) } \\
\cline { 2 - 4 } & Min & Max & Avg \\
\hline$\lambda$ iteration & 62456.6391 & NA & NA \\
\hline Hopfield model & 62456.6341 & NA & NA \\
\hline BBO & 62456.7926 & NA & 62456.6331 \\
\hline QGSO & 62456.6330 & 62456.63337 & NA \\
\hline GAMS & 62456.633 & NA & $\mathbf{6 2 4 5 6 . 6 3 3 1 1}$ \\
\hline PSOGSA & $\mathbf{6 2 5 4 5 6 . 6 3 3 0 9}$ & $\mathbf{6 2 4 5 6 . 6 3 3 1 0}$ & \\
\hline
\end{tabular}

Table 12: Comparison of convergence result for 54 unit system

\begin{tabular}{|c|c|c|c|}
\hline \multirow{2}{*}{ Method } & \multicolumn{3}{|c|}{ Generation Cost(\$/hr) } \\
\cline { 2 - 4 } & Min & Max & Avg \\
\hline DE & 25237 & NA & NA \\
\hline PSO & 23625 & NA & NA \\
\hline ALHN & 23368 & NA & $\mathbf{2 2 4 3 2 . 2 9 2 8}$ \\
\hline PSOGSA & 22432.2510 & 22432.3347 & \\
\hline
\end{tabular}




\section{B) Computational effciency}

The statistical analysis in terms of minimum cost and average computational time is presented in Table 13 for test case I, III and IV. For repeated 20 trials minimum cost and average computational time is less and better than the mentioned methods. The results obtained are compared with the recent reported methods and shows the efficiency of algorithm.

Table 13: Comparison of Computational Efficiency

\begin{tabular}{|c|c|c|c|}
\hline Test Case & Method & $\operatorname{Min} \cos t(\$ / h r)$ & Time /Iter (sec) \\
\hline \multirow{10}{*}{$\begin{array}{l}6 \text { unit } \\
\text { system }\end{array}$} & PSO & 15450 & 14.89 \\
\hline & GA & 15459 & 41.58 \\
\hline & NPSO-LRS & 15450 & NA \\
\hline & ABF-NM & 15443.8164 & NA \\
\hline & $\mathrm{DE}$ & 15449.766 & 0.0335 \\
\hline & SOH-PSO & 15446.02 & 0.0633 \\
\hline & HHS & 15449 & 0.14 \\
\hline & BBO & 15443.096 & 0.0325 \\
\hline & Hybrid SI-based HS & 15442.8423 & 0.9481 \\
\hline & PSOGSA & 15442.3930 & 0.0420 \\
\hline \multirow{6}{*}{20 unit system } & $\lambda$ iteration & 62456.6391 & 0.033757 \\
\hline & Hopfield model & 62456.6341 & 0.006355 \\
\hline & $\mathrm{BBO}$ & 62456.7926 & 0.29282 \\
\hline & QGSO & 62456.6330 & NA \\
\hline & GAMS & 62456.633 & NA \\
\hline & PSOGSA & 625456.63309 & 0.0497 \\
\hline \multirow{4}{*}{54 unit system } & $\mathrm{DE}$ & 25237 & 282.4 \\
\hline & PSO & 23625 & 136.4 \\
\hline & ALHN & 23368 & 1.65 \\
\hline & PSOGSA & 22432.2510 & 0.0416 \\
\hline
\end{tabular}

\section{C) Robustness}

The search capability of heuristic algorithm can not be analyzed with a single trial because of its randomness. Therefore many trials are required with different initializations. Table 10, 11, 12 shows the minimum cost, maximum cost, average cost over 20 trials for 6 unit with RRL and POZ, 20 unit with losses and 54 unit system. The results show that PSOGSA is more consitent than other reported method as it provides lower average cost while satisfying the different constraints of the various test cases.

\section{Conclusion}

In this paper hybrid PSOGSA algorith $\mathrm{m}$ based on the abilities of PSO and GSA is successfully employed to solve ELD problem. Here $\alpha c_{i}$ is used to accelerate the search space and gbest to exploit the best solution so far. The hybrid PSOGSA approach has been tested on four different standard test systems out of which first case is modeled using non linear characteristics like ramp rate limits and prohibited zone. A comparative study is carried out with the recent reported methods. From the results obtained it is seen that the PSOGSA approach affirms the effective high quality solution for ELD problem. The PSOGSA approach has the convergence speed faster than PSO and GSA. In future the algorithm can be use effectively to solve smooth and non-smooth constraint and complex ELD problem.

\section{Acknowledgments}

Authors are thankful to the Director, Madhav Institute of Technology \& Science, Gwalior (M.P) India for providing support and facilities to carry out this research work.

\section{References}

[1] Wood A.J., Wollenberg B.F., Power Generation Operation and Control, New York: Wiley, 1984.

[2] Walter D.C., Sheble G.B., Genetic Algorithm Solution of Economic Load Dispatch with Valve Point Loading, IEEE Transcations on Power System, 1993 (8), 1325 1332. 
[3] Wang, Shahidepour S.M., Effects of Ramp Rate Limits on Unit Commitment and Economic Dispatch, IEEE transcations on Power System, 1993, 8(3):1341 1350.

[4] Oreo S.O., Irving M.R., Economic Dispatch of Generators with Prohibited Opertaing Zones:A Genetic Algorithm Approach,IEE Proceedings, Generation, Transmission and Distribution, 1996,143(6).

[5] Chen C.L., and Wang S.C., Branch and bound scheduling for thermal generating units, IEEE Trans. On Energy Conversion, 1993, 8(2):184 189.

[6] K.Y. Lee, et al, Fuel cost minimization for both real and reactive power dispatches, IEE Proc. C, Gener. Trsns. \& distr., 1984, 131(3): 85 93.

[7] Shoults R.R., A Dynamic Programming Based Method for Developing Dispatch Curves when Incremental Heat Rate Curves Are NonMonotonically Increasing, IEEE Transcations on Power System, 1986,1,10 16.

[8] Gaing Z.L., Particle Swarm Optimization to Solving the Economic Dispatch Considering the Generator Constraints, IEEE Trans. On power systems, 2003,18(3):1187 1195.

[9] Sinha N., Chakrabarti R. and Chattopadhyay P.K., Evolutionary Programming Techniques for Economic Load Dispatch, IEEE Transcations on Evolutionary Computation, 2003,20(1):83 94.

[10] Noman Nasimul, Iba Hitoshi, Differential evolution for economic load dispatch problems, Electric Power Systems Research, 2008, 78:1322 1331.

[11] Ching-Tzong S., Chien-Tung L.,New approach with a Hopfield modeling framework to economic dispatch, IEEE Trans. Power Syst., 2000,15(2):541 545.

[12] Immanuel Selvakumar A., Thanushkodi K., A New Particle Swarm Optimization Solution to Nonconvex Economic Dispatch Problems, IEEE Trans. Power Syst., 2007, 22(1): 42 51.

[13] Chaturvedi K.T., Pandit M., Srivastava L.,SelfOrganizingHierarchical Particle Swarm Optimization for Non-Convex Economic Dispatch, IEEE Trans. Power Syst., 2008, 23(3): 1079 1087.

[14] Panigrahi B.K. and Pandi V.R., Bacterial foraging optimization nelder mead hybrid algorithm for economic load dispatch, IET Gener. Transm. Distrib., 2008, 2(4): 556 565.

[15] Bhattacharya A., Chattopadhyay P.K., Biogeography Based optimization for different economic load dispatch problems, IEEE Trans. Power Syst., 2010,25(2):1064 1077.

[16] Moradi-Dalvand M., Mohammadi-Ivatloo B., Najafi A., Rabiee A., Continuous quick group search optimizer for solving non-convex economic dispatch problems, electric power system research, 2012, 93: 93 105.

[17] Biswas A., Dasgupta S., Panigrahi B.K., Pandi V.R., Das S., Abraham A., Badr Y., Economic load dispatch using a chemotactic differential evolution algorithm, Hybrid Artificial Intelligence Systems, 2009,5572, 252 260.

[18] Pandi V.R., Panigrahi B.K., Bansal R.C., Das S., Mohapatra A., Economic Load Dispatch Using Hybrid Swarm Intelligence Based Harmony Search Algorithm, Electric Power Components and Systems, 2011,39(8): 751 767.

[19] Xin-She Yang, Seyyed Soheil Sadat Hosseinib, Amir Hossein Gandomic, Firefly Algorithm for solving non-convex economic dispatch problems with valve loading effect, Applied Soft Computing, 2012,12, 1180 1186.

[20] Mirjalili S, Mohd Hashim S Z, A new Hybrid PSOGSA Algorithim for Function Optimization, IEEE International Conference on Computer Information and application (ICCIA 2010), China , 2010, 374 377.

[21] Ioannis G., Damousis, Anastasios G. Bakirtzis and Petros S. Dokopoulos, Network-Constrained Economic Dispatch Using Real-Coded Genetic Algorithm. IEEE Trans on power system, 2003, 18(1):198 204.

[22] Dixit Gaurav Prasad, Dubey Hari Mohan, Pandit Manjree, Panigrahi B.K., Economic Load Dispatch using Artificial Bee Colony Optimization. International Journal of Advanced in Electronics Engineering. 2011, 129 124.

[23] Vishwakarma Kamlesh Kumar, Dubey Hari Mohan, Pandit Manjaree, Panigrahi B.K., Simulated annealing approach for solving economic load dispatch problems with valve point loading effects, International Journal of Engineering Science and Technology, 2012, 4(4): 60 72.

[24] Bisen Devendra, Dubey Hari Mohan, Pandit Manjaree and Panigrahi B. K., Solution of Large Scale Economic Load Dispatch Problem using Quadratic Programming and GAMS: A Comparative Analysis, Journal of Information and Computing Science(jic.org.uk), 2012,7(3): 200 211.

[25] Dieu V.N., Schegner P., Real Power Dispatch on Large Scale Power Systems by Augmented Lagrange Hopfield Network, International Journal of Energy Optimization and Engineering, 2012,1(1):19 38. 


\section{Authors' Profiles}

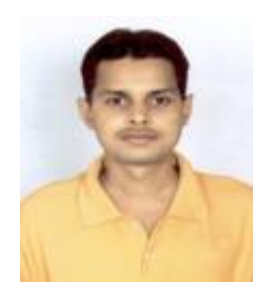

Hari Mohan Dubey obtained his M.E. degree in Electrical Engineering from Madhav Institute of Technology \& Science Gwalior (India) in 2002. He is currently working as Assistant Professor in Department of Electrical Engineering, M.I.T.S., Gwalior, (India). His areas of research are Computational intelligence algorith $m$ and their applications to power system.

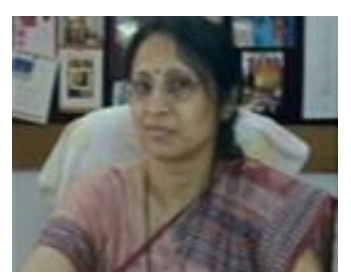

Manjaree Pandit obtained her M. Tech degree in Electrical Engineering from Maulana Azad College of Technology, Bhopal, (India) in 1989 and Ph.D. degree from Jiwaji University Gwalior (India) in 2001. She is currently working as Professor in Department of Electrical Engineering, M.I.T.S., Gwalior, (India). Her areas of interest are Power System Security Analysis, Optimization using soft computing/ evolutionary methods, ANN and Fuzzy neural applications to Power System.

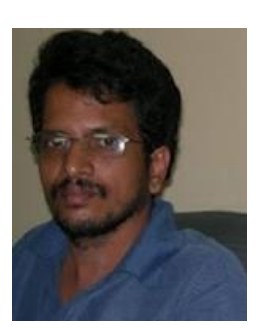

Bijaya Ketan Panigrahi obtained his M. Tech degree in Electrical Engineering from University College of engineering, Burla, sambalpur, Orissa in 1995 and Ph.D. degree from sambalpur University Orissa (India) in 2004. He is currently working as Associate

Professor in Department of Electrical Engineering, IIT, Delhi,(India). His areas of research includes the study of advanced signal processing techniques, Computational intelligence algorithm and their applications to electrical engineering, in particular to domain of power system. He is also works in area of application of evolutionary computing techniques to solve problem related to power system planning, operation and control.

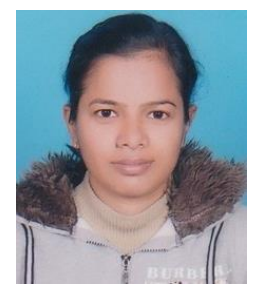

Mugdha udgir obtained her B.E. degree in Electrical Engineering from MPCT, Gwalior (India) in 2009. She is presently doing M.E. in Industrial Systems and Drives (ISD) from M.I.T.S., Gwalior, (India).
How to cite this paper: Hari Mohan Dubey, Manjaree Pandit, B.K. Panigrahi, Mugdha Udgir,"Economic Load Dispatch by Hybrid Swarm Intelligence Based Gravitational Search Algorithm", International Journal of Intelligent Systems and Applications(IJISA), vol.5, no.8, pp.21-32, 2013. DOI: 10.5815/ijisa.2013.08.03 